\title{
Biological Activity of Two Tombusvirus Proteins Translated from Nested Genes Is Influenced by Dosage Control via Context-Dependent Leaky Scanning
}

\author{
Herman B. Scholthof, Bénédicte Desvoyes, Joan Kuecker, and Elizabeth Whitehead \\ Department of Plant Pathology and Microbiology, Texas A\&M University, College Station 77843, U.S.A. \\ Accepted 3 May 1999.
}

\begin{abstract}
Tomato bushy stunt virus (TBSV) encodes a small gene (p19) nested within the cell-to-cell movement gene (p22), and their translation yields two proteins with separate activities for virus spread and symptom induction. The objective of this study was to determine the biological relevance associated with the translational mechanism responsible for expression of the nested p22 and p19 genes. Introduction of site-specific mutations to optimize the translational start site context of $\mathbf{p 2 2}$ caused a substantial shift in the ratio of the two proteins, mainly because it dramatically reduced the otherwise abundant levels of p19 protein accumulation in vitro and in vivo. Changes in the dosage or ratios of $\mathrm{p} 22$ and $\mathrm{p} 19$ proteins failed to noticeably affect virus replication or movement in Nicotiana spp. that support a systemic infection. In contrast, bio-assays with hypersensitive Nicotiana hosts illustrated that a substantially elevated $\mathbf{p 2 2 / p 1 9}$ protein ratio increased the size of 19 protein-mediated lesions whereas those induced by the $\mathbf{p 2 2}$ protein tended to be smaller. The reduced levels of p19 protein prevented the onset of a lethal apical necrosis in systemically infected Nicotiana benthamiana plants. Furthermore, the increased p22/p19 protein ratio impaired the ability of TBSV to systemically invade spinach plants. These results suggest that control of tombusvirus p22 and p19 protein ratios and dosage through contextdependent leaky scanning provides a co-translational mechanism to coordinate their biological activities.
\end{abstract}

Genetic systems to examine the mechanisms influencing virus protein ratios or dosage in vivo can potentially reveal new information on the coordination of virus protein synthesis and biological activities. A system to investigate some of these aspects is provided by tomato bushy stunt virus (TBSV), which encodes two overlapping genes (p22 and p19) that are translated from the same subgenomic RNA (sgRNA), to yield different amounts of two proteins with separable activities for virus spread and symptom induction (Scholthof et al. 1995b).

TBSV particles encapsidate a single copy of a positivesense, single-stranded RNA genome of 4,775 nucleotides (nt),

Corresponding author: Herman B. Scholthof; Telephone: 1-409-8621495; Fax: 1-409-845-6483; E-mail: herscho@acs.tamu.edu with five major open reading frames (ORFs) (Hearne et al. 1990). The genomic RNA serves as an mRNA for the translation of two $5^{\prime}$ proximal genes that encode a $33-\mathrm{kDa}$ protein (p33) and a read-through product of $92 \mathrm{kDa}(\mathrm{p} 92)$, respectively, which are both required for replication (Scholthof et al. $1995 \mathrm{~d}$ ). The 41-kDa coat protein gene (p41) is located farther downstream and its translation occurs from sgRNA1, whereas the two $3^{\prime}$ proximal genes (p22 and p19) are translated from sgRNA2 (Hayes et al. 1988; Hillman et al. 1989; Johnston and Rochon 1990; Rochon and Johnston 1991). The p22 gene encodes a relatively low abundance, membrane-bound protein of $22 \mathrm{kDa}$ that functions as the cell-to-cell movement protein (Scholthof et al. 1995b; Chu et al. 1999). This product also elicits the activation of a hypersensitive response-like (HRlike) defense in Nicotiana glutinosa (Scholthof et al. 1995a). Nested within the p22 gene is the p19 ORF, which encodes a highly abundant, cytoplasmic protein of $19 \mathrm{kDa}$ that is required for effective systemic invasion of some plants (e.g., spinach) (Scholthof et al. 1995b). In addition, the p19 protein is responsible for the induction of severe systemic symptoms on $N$. benthamiana, whereas in N. tabacum it elicits an HRlike defense mechanism (Scholthof et al. 1995a).

The objective of the present study was to determine the regulatory mechanism and biological relevance of differential accumulation of the TBSV p22 and p19 proteins. The results indicate that nucleotide sequence contexts surrounding the p22 start codon promote context-dependent leaky scanning of ribosomes leading to high levels of translation from the downstream p19 start codon. Alteration of this co-translational regulation of differential gene expression results in deviating levels of p22 and p19 protein accumulation, which influences host-dependent onset of local or systemic symptoms, or systemic invasion.

\section{RESULTS}

Sequences upstream of the p22 and p19 start codons affect their in vitro translation efficiency.

Although the start codon of the p19 gene is positioned downstream of the start codon for p22 (Fig. 1B), previous results suggested that the p19 protein accumulated to very high levels (Scholthof et al. 1995b). Nucleotide sequence comparisons with the consensus start codon sequences of plant mRNAs 
(AACAAUGGC) (Lutcke et al. 1987) revealed that the sequence AACCAUGGA, surrounding the italicized start codon of p19, shows a high degree of identity with the consensus sequence, as illustrated by underlining. However, the sequences encompassing the start codon of p22 (GUUCAUGGA) form a context that is notably less similar to the consensus.

To investigate the effect of translational start site contexts on protein accumulation, a mutant clone pHST5 (Fig. 1C) was generated in which the predicted sub-optimal translation initiation context sequence of p22 was replaced by the presumably optimal sequence of the downstream p19, and vice versa. However, this manipulation also introduced two amino acid changes from Lys-Pro to Ser-Ser in p22 (Fig. 1C). To avoid these substitutions, pHST13 was generated, in which the translational context of p22 was changed from sub-optimal to optimal without altering the context of p19 (Fig. 1C).

Synthetic transcripts resembling sgRNA2 were generated in vitro from polymerase chain reaction (PCR)-amplified DNA fragments, followed by in vitro translation and sodium dodecyl sulfate-polyacrylamide gel electrophoresis (SDS-PAGE). The results obtained with wild-type sgRNA2 show that the p19 protein was translated to higher amounts, compared with the p22 protein (Fig. 2, lane T). The more intense signal for the p19 protein compared with that for $\mathrm{p} 22$ is not due to incorporation of more labeled methionines per polypeptide; in fact there are 5 methionines in the p22 polypeptide compared with only 3 for the p19 protein. Comparison between the lanes in Figure 2 may be affected by experimental variations, but the most relevant information pertains to the $\mathrm{p} 22 / \mathrm{p} 19$ protein ratio obtained within each sample. Translation of sgRNA2 from pHST5, with an improved p22 start site context and a deteriorated context for $\mathrm{p} 19$, resulted in a strong reduction of p19 protein translation, and therefore an increased p22/p19 protein ratio (Fig. 2, lane 5). In vitro translation of sgRNA2 transcripts from pHST13 showed that improvement of the start site context of p22, without affecting the context of p19, was in itself sufficient to decrease the amount of p19 protein accumulation (Fig. 2, lane 13). For unknown reasons, the p19 and p22 in vitro translation products consistently migrated slightly higher than their predicted sizes. However, the identity of the products from pHST5- and pHST13-derived transcripts was confirmed with sgRNA2 of pHS136 and pHS157 as templates for in vitro translation experiments (Fig. 2, lanes 136 and 157). These mutants contain premature stop codons preventing the accumulation of either $\mathrm{p} 22$ or $\mathrm{p} 19$ proteins, respectively (Scholthof et al. 1995b).

A

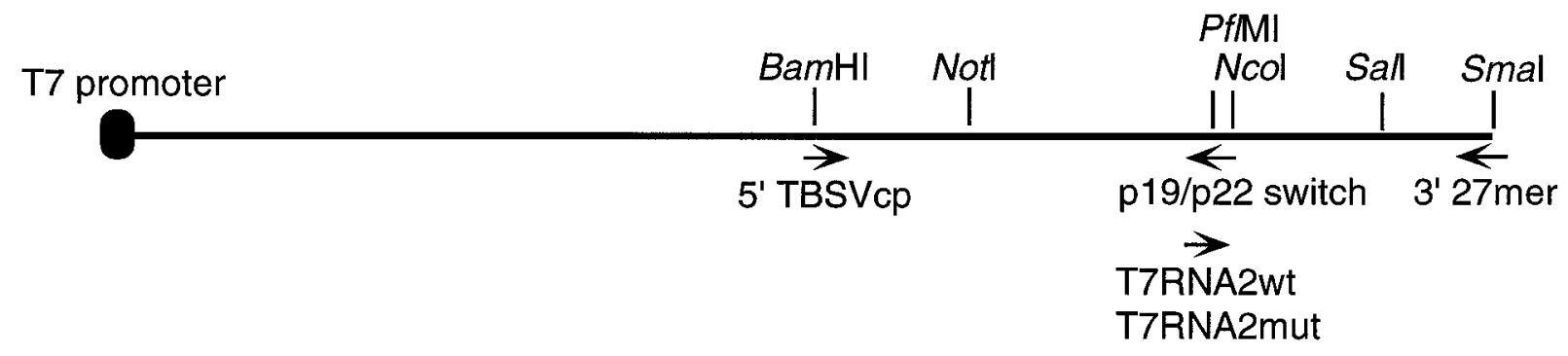

$\mathbf{B}$

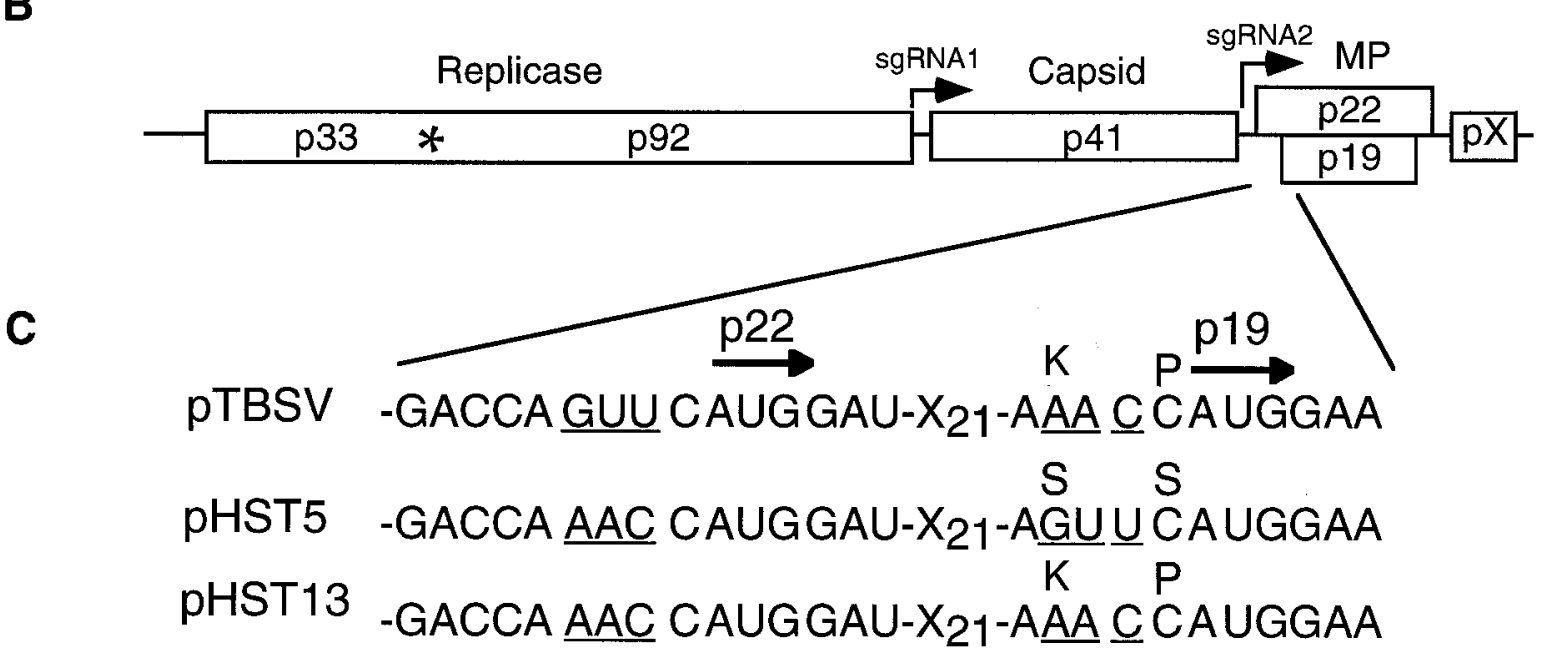

Fig. 1. Schematic representation of the tomato bushy stunt virus (TBSV) genome and details of mutants. A, Full-length cDNA (horizontal line) is shown together with the location of the T7 promoter, selected restriction sites, and position and orientation (arrows) of oligonucleotide primers used in this study. B, Genome organization of TBSV. Boxes indicate open reading frames; predicted sizes of their products are given in $\mathrm{kDa}$, and functions are provided on top (MP, movement proteins; $\mathrm{pX}$, function is unknown). The asterisk depicts the amber stop codon for translational read-through of p33 to express p92. Transcription initiation sites of the two subgenomic RNAs (sgRNA1 and -2) are depicted by broken arrows. C, Translational start site context mutations. Sequences surrounding the start codons (arrows) of p22 and p19 on RNA transcribed from wild-type TBSV (pTBSV) and the mutants pHST5 and pHST13 are shown. Underlined sequences of plasmid analogs were targeted for mutation; the effect on amino acid sequences of p22 protein is shown by single letters above the sequence. $X_{21}$ indicates the presence of 21 spacer nucleotides that are identical for wild type and the mutants. 
The higher levels of $\mathrm{p} 19$ protein versus p22 protein upon in vitro translation of wild-type TBSV sgRNA2 in a rabbit reticulocyte system (Fig. 2, lane T) mimics the ratio of signal intensity observed in vivo (Scholthof et al. 1995b). Conversely, translation of wild-type TBSV sgRNA2 in wheat germ extracts yielded levels of p22 protein in excess of p19 protein (data not shown), which agrees with results obtained during in vitro translation experiments with cucumber necrosis tombusvirus (CNV) sgRNA2 analogues (Johnston and Rochon 1996). However, regardless of the differences between the two translation systems, TBSV sgRNA2 transcripts of pHST5 and pHST13 consistently yielded reduced levels of p19 protein, compared with wild-type TBSV sgRNA2.

\section{Translational start site contexts}

\section{control protein accumulation in vivo.}

Transfection of transcripts from pTBSV-100, pHST5, or pHST13 into $N$. benthamiana protoplasts showed that the mutations had no noticeable debilitating effect on replication of the TBSV gRNA or transcription of the sgRNAs (Fig. 3), although minor effects cannot be excluded. The main emphasis in the lower three panels in Figure 3 involves a comparison of protein ratios within each protoplast sample, rather than between samples. This consistently revealed that the p33 protein was readily detectable in all samples, and the p22/p19 protein ratio was substantially increased for pHST13, mainly because the p19 protein failed to accumulate to detectable levels (Fig. 3). As for pHST13, the p19 protein did not accumulate either in protoplasts transfected with RNA from pHST5, and, unexpectedly, neither was the mutant $\mathrm{p} 22$ protein with the two serine substitutions detectable.

\section{Cell-to-cell movement is not impaired by variations in p22 or p19 protein accumulation.}

A bio-assay for cell-to-cell movement was required to determine whether the shift in $\mathrm{p} 22 / \mathrm{p} 19$ protein ratio for $\mathrm{pHST} 13$, or the undetectable levels of $\mathrm{p} 22$ protein produced by RNA from pHST5, had any biological effect on the cell-to-cell movement function. For this purpose the mutated fragments of pHST5 and pHST13 were introduced into a TBSV construct

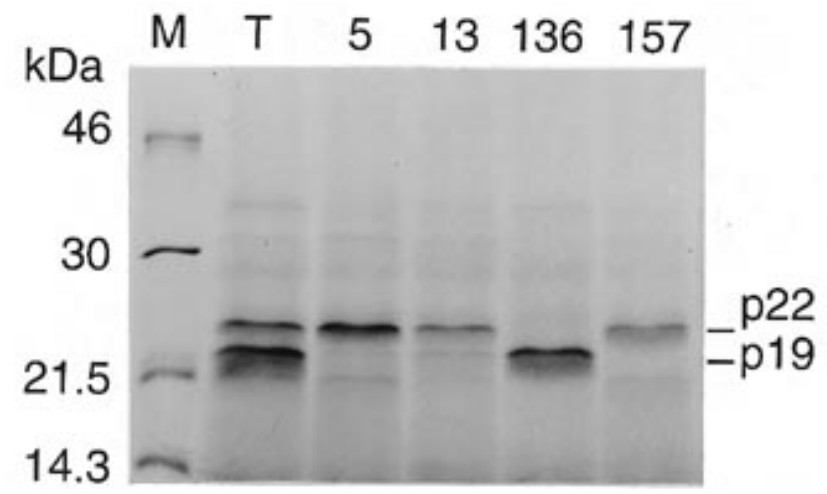

Fig. 2. In vitro translation in a rabbit reticulocyte lysate of uncapped, synthetic subgenomic (sg) RNA2 of wild-type tomato bushy stunt virus (TBSV) (T) and the translational start site context mutants pHST5 (5) and pHST13 (13). Position of size markers (M) and their molecular masses in $\mathrm{kDa}$ are indicated. Translation of the sgRNA2 from mutants pHS136 (136) and pHS157 (157) containing premature stop codons in the p22 and p19 gene, respectively (Scholthof et al. 1995b), confirms the identity of the proteins.
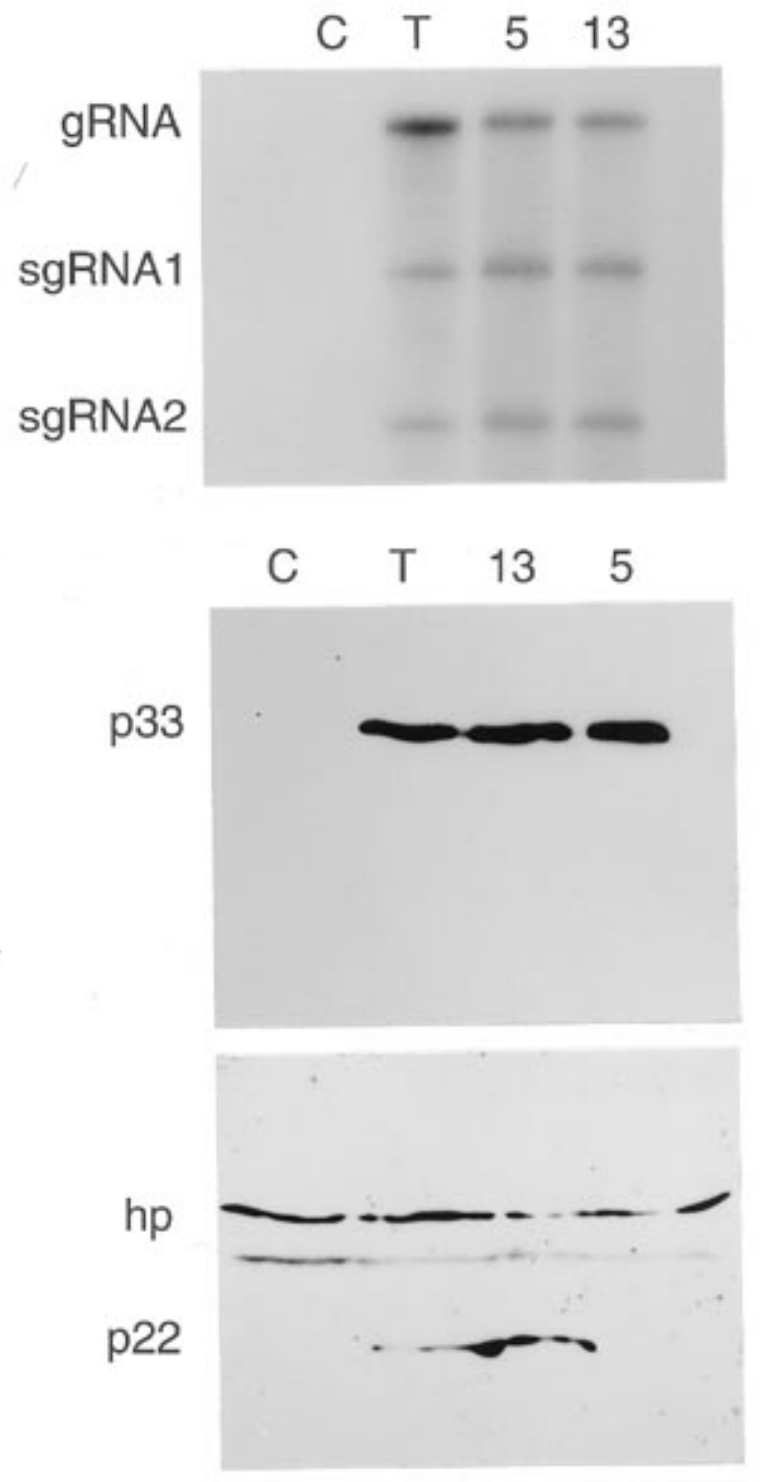

p19

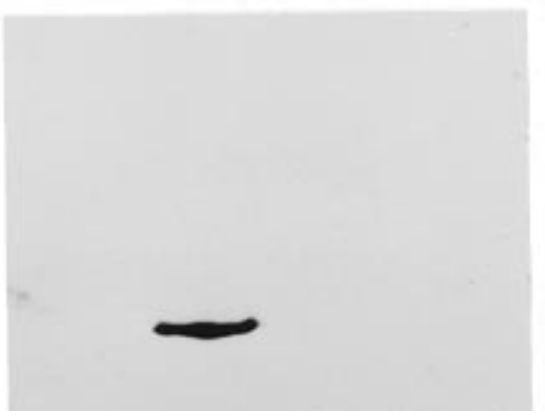

Fig. 3. Replication and gene expression in Nicotiana benthamiana protoplasts. Transfections were carried out with transcripts from either wildtype tomato bushy stunt virus (TBSV) (T), pHST5 (5), or pHST13 (13). Transcripts from either replicase-deficient mutants pHS54 (Scholthof et al. 1993a) or pHS9 (Scholthof et al. 1995d) were used as negative controls (C) for the hybridization (top panel) or immuno-detection (lower three panels). Top panel: Autoradiogram of an RNA hybridization blot to visualize the accumulation of genomic RNA (gRNA) and subgenomic RNAs (sgRNA1 and sgRNA2). Lower panels: Autoradiograms upon chemiluminescent Western (immunoblot) assays for detection of the p33, p22, and p19 proteins, respectively. The cross reaction of the p22 antiserum with host proteins (hp) is indicated. 
in which the coat protein was replaced with the $\beta$-glucuronidase (GUS) gene to permit histochemical visualization of cell-to-cell movement (Scholthof et al. 1995b). The transfer of the mutations of pHST5 into the GUS derivative yielded pHST23, whereas pHST24 contained the same mutations as pHST13. The movement of viral RNA derived from pHST23 and pHST2 4 was compared with that of the parental construct pHS45 (Scholthof et al. 1993b), which contains the wild-type translational start site contexts. Histochemical assays demonstrated that inoculations with RNA from pHS45, pHST23, or pHST24 all gave rise to virus infections that spread efficiently from cell to cell in N. clevelandii (Fig. 4). Similar results were obtained upon infection of $N$. benthamiana or Chenopodium quinoa (data not shown). The results suggest that neither the shift in $\mathrm{p} 22 / \mathrm{p} 19$ protein ratio (pHST13) nor the inability to detect mutant p22 protein levels (pHST5) substantially affected cell-to-cell movement.

\section{Effects of p22/p19 protein ratios on HR-like defenses in resistant hosts.}

Necrotic local lesion hosts ( $N$. tabacum and N. glutinosa) were inoculated with plant sap from $N$. benthamiana plants systemically infected upon inoculation with transcripts from either pTBSV-100, pHST5, or pHST13. Plant sap inoculations on the local lesion Nicotiana hosts were preferred because of the superior infectivity compared with transcript inoculations on these plants. Passaging through $N$. benthamiana was permissible because p22 and p19 mutants display a remarkable stability based on the consistency of phenotypes (data not shown).

Previous findings showed that the TBSV p19 protein is responsible for the elicitation of necrotic local lesions on $N$. tabacum (Scholthof et al. 1995a). To determine the influence of p19 protein dosage on this HR-like defense, $N$. tabacum was inoculated with the mutants. These tests showed that the mutants gave rise to a mixture of either chlorotic or enlarged necrotic lesions, compared with the small, necrotic lesions induced by wild-type TBSV (Fig. 5). The phenotype of the local lesions varied noticeably with environmental conditions (light intensity, temperature) prior to inoculation, especially for pHST5 (data not shown). Nevertheless, in all cases the reduced p19 accumulation resulted in enlarged local lesions on the $N$. tabacum leaves.

$N$. glutinosa was used to determine the effect of the mutations on the p22-mediated elicitation of local lesions. In this host, the increased ratio of elicitor (p22 protein) versus the generalized necrosis inducer (p19 protein) resulted in the onset of slightly smaller (pHST13) local lesions, compared with those elicited by wild-type TBSV (Fig. 5). Substantially smaller lesions were obtained upon inoculation of $N$. glutinosa with virus derived from $\mathrm{pHST5}$.

\section{Effects on systemic symptoms and virus protein accumulation in $N$. benthamiana.}

Previous results demonstrated that the p19 protein is responsible for the induction of a systemic lethal necrosis in $N$. benthamiana (Scholthof et al. 1995a). To determine the effect of the shifts in ratios and dosage of the $\mathrm{p} 22$ and $\mathrm{p} 19$ proteins on systemic infections and symptoms, $N$. benthamiana plants were inoculated with transcripts from pHST5 and pHST13 (Fig. 6A). The results show that the mutations in pHST5 and
pHST13 generally prevented the induction of a lethal necrosis; instead, severe systemic mosaic with stunting and localized necrotic symptoms developed (Fig. 6A).

Immunoblot assays were performed to determine the effect of mutations on the accumulation profile of virus proteins in inoculated $N$. benthamiana leaves at different times post inoculation (Fig. 7A). Similar protein accumulation profiles were observed in upper systemically invaded leaves (data not shown). Although variations in p33 protein levels were observed, repeated tests failed to reveal consistent effects of the mutations in pHST5 and pHST13 on p33 protein accumulation. Furthermore, as was also emphasized for Figure 3, the most relevant comparisons involve the ratios of the different proteins within the same sample. Parallel RNA hybridization tests showed that the levels of p33 protein were a direct reflection of the accumulation of viral RNA (data not shown). Unexpectedly, the amount of p41 coat protein was reduced in the leaves infected with the mutants (Fig. 7A). This specific effect is best illustrated for the lanes with pHST13 in $N$. benthamiana that show equal or higher levels of $\mathrm{p} 33$ protein, compared with the lanes with wild-type TBSV, whereas the p41 coat protein is substantially reduced.

The results in Figure 7A demonstrate that the improvement of the p22 translational start site context on RNA from pHST13 increased the $\mathrm{p} 22 / \mathrm{p} 19$ protein ratio. This effect was mostly due to a dramatic decrease in p19 protein accumulation, but early after inoculation increased levels of $\mathrm{p} 22$ protein also contributed to this phenomenon. As was observed in protoplasts, p22 protein could not be detected in plants infected with RNA from pHST5. The improvement of the p22 context in pHST13, and the additional mutations in pHST5 that deteriorated the context for $\mathrm{p} 19$, only slightly further decreased the levels of p19 protein accumulation (Fig. 7A). Comparison of potato virus $\mathrm{X}(\mathrm{PVX})$-mediated expression of wild-type versus pHST5 sgRNA2 also showed that the mutations reduced $\mathrm{p} 19$ protein accumulation from this heterologous expression system, whereas the mutant $\mathrm{p} 22$ protein was again undetectable (data not shown).

\section{Influence of mutations on systemic invasion of spinach.}

Because the p19 protein is required for effective systemic invasion of spinach plants (Scholthof et al. 1995b), the mutants provided an opportunity to determine the effect of reduced p19 protein accumulation on virus spread in this host. Immunoblot analyses of inoculated spinach leaves (Fig. 7B) revealed a protein accumulation profile similar to that observed for $N$. benthamiana (Fig. 7A). For the experimental results shown in Figure $7 \mathrm{~B}$, the reduction in $\mathrm{p} 41$ coat protein in spinach is not as substantial as observed in $N$. benthamiana (Fig. 7A). However, more pronounced effects have occasionally been observed (data not shown). Nevertheless, in combination with the RNA analyses (Fig. 7C), these experiments failed to detect obvious effects of the mutations on infectivity in inoculated spinach leaves during the first few days after inoculation.

Inoculation of the first true leaves of spinach plants with pHST5 and pHST13 transcripts resulted in the onset of local necrotic lesions at 5 to 6 days post inoculation (dpi) (Fig. 6B). Under these same conditions $\left(180 \mu \mathrm{E} \mathrm{s}^{-1} \mathrm{~m}^{-2}\right.$ light intensity, $23^{\circ} \mathrm{C}$ daytime temperature for $14 \mathrm{~h}, 20^{\circ} \mathrm{C}$ at night) such lesions were less conspicuous on the first true leaves inoculated 
with wild-type TBSV (Fig. 6B). In this context it is important to note that variations in growing conditions, age of the plant, position of inoculated leaf, and source of inoculum all influence the symptom phenotype on inoculated leaves, as was also observed previously (Scholthof et al. 1993b, 1995b). However, within experiments for this study, a difference between mutants and wild type appeared consistent.

Wild-type TBSV rapidly (6 to $7 \mathrm{dpi}$ ) invaded spinach systemically but the pHST5 mutant consistently failed to invade upper noninoculated spinach leaves (Fig. 6B). Inoculation of very young spinach plants (fourth leaf stage) with pHST13 transcripts would permit limited infection of upper leaves (Fig. 6B), as confirmed by immunoblot analyses (data not shown), but those plants would display attenuated symptoms. Despite the limited ability of the pHST13 mutant to spread in young spinach plants, in contrast to wild-type TBSV, neither pHST5 nor pHST13 infections were able to invade upper leaves upon inoculation of plants that were physiologically more mature (sixth to eighth leaf stage) (Fig. 6B), as confirmed by Western (immunoblot) analysis (data not shown).

\section{DISCUSSION}

\section{Context-dependent leaky scanning regulates differential expression of p22 and p19.}

The influence of leaky scanning on translation of plant viral RNAs has previously been studied through in vitro translation experiments (Dinesh-Kumar and Miller 1993; Johnston and Rochon 1996; Sivakumaran and Hacker 1998; Zhou and Jackson 1996). These were sometimes performed in combination with transient in vivo assays with DNA constructs, with a small portion of the viral cDNA fused to a reporter gene (Dinesh-Kumar and Miller 1993; Johnston and Rochon 1996; Sivakumaran and Hacker 1998), or by transfection of protoplasts with replication competent genomes containing a reporter gene (Zhou and Jackson 1996).

Because the TBSV RNA segment containing the p22 and p19 start codons is not required for replication (Scholthof et al. 1995b) mutations were permissible in that region to determine the effect on infectivity in plants. This feature, in combi-

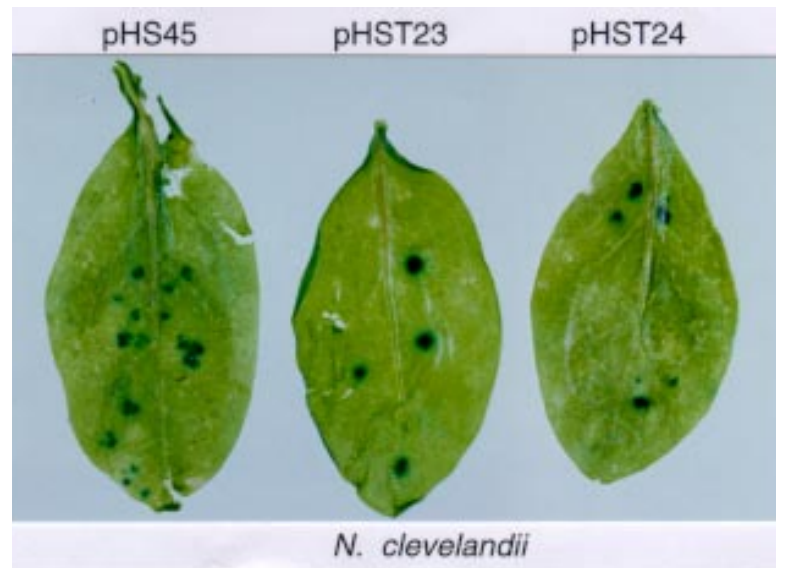

Fig. 4. Histochemical $\beta$-glucuronidase (GUS) assay for comparison of cell-to-cell movement. Nicotiana clevelandii leaves 4 days after inoculation with transcripts of the plasmids indicated above the leaves. As previously reported (Scholthof et al. 1995b), inactivation of the p22 gene prohibits the formation of blue foci. nation with the high levels of TBSV gene expression (Scholthof et al. 1993b) and the availability of sensitive immuno-detection assays for all viral proteins (Scholthof et al. 1995b, 1995c, 1995d), permitted direct examination of the effects of p22 and p19 translational start site contexts on accumulation of proteins during infection of protoplasts and whole plants. These unique, advantageous features provided the opportunity to perform a detailed study on translational control of overlapping plant virus genes to monitor the direct effect of variations in protein accumulation and associated biological relevance.

Translational initiation at the $5^{\prime}$ proximal start codon on a eukaryotic mRNA depends on various factors, including the sequence composition immediately adjacent to the start codon (Kozak 1981, 1997). Presence of nucleotides that form a suboptimal context can promote leaky scanning of the small ribosomal subunit until a favorable start codon is reached (Kozak 1995). The TBSV sgRNA2 nucleotide sequence surrounding the start codon of p22 (GUUCAUGGA) shows a low degree of similarity with the consensus sequence for optimal translation initiation of plant mRNAs (AACAAUGGC) (Lutcke et al. 1987), whereas the downstream start codon of p19 (AACCAUGGA) forms a context that is notably more similar. The present data reveal that replacement of the p22 start codon context with the context of p19 slightly enhances p22 protein accumulation in vitro and in vivo. This increase in $\mathrm{p} 22$ protein is accompanied by a severe decrease in translation of the downstream p19. This interpretation is in agreement with a previous observation that the fusion of sequences upstream
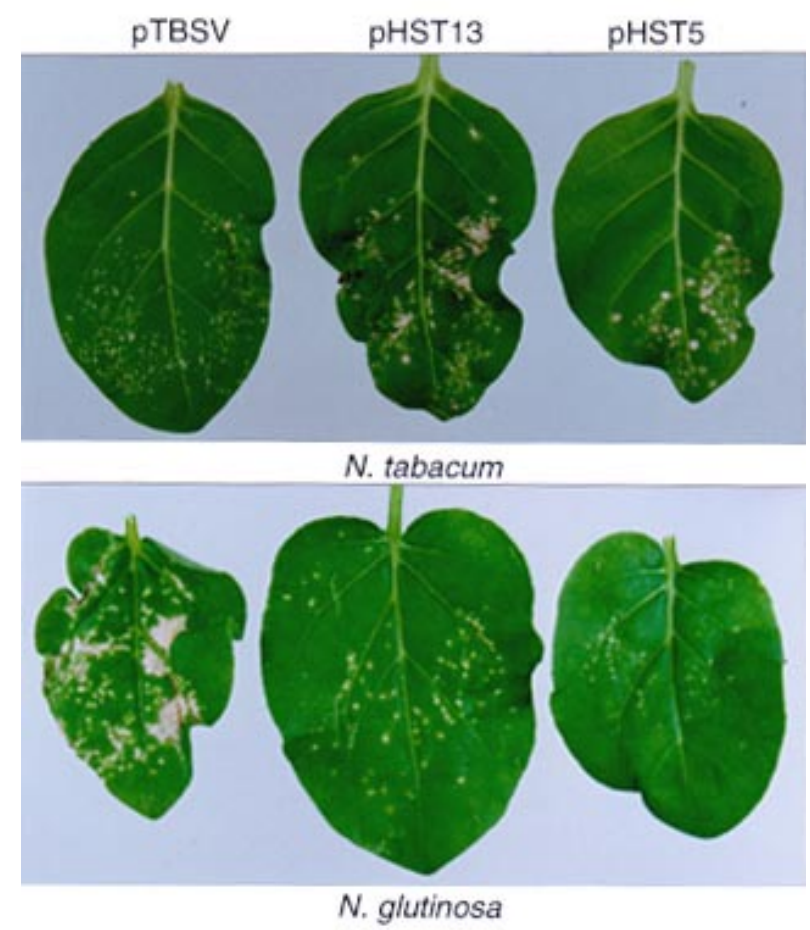

Fig. 5. Effect of translational start site context mutations on the phenotype of hypersensitive response (HR)-like local lesion formation. Leaves were harvested at 6 days post inoculation with inoculum derived from plasmids indicated on top. Upper panel: p19-induced local lesions on Nicotiana tabacum leaves; bottom panel: p22-induced local lesions on N. glutinosa. 
A

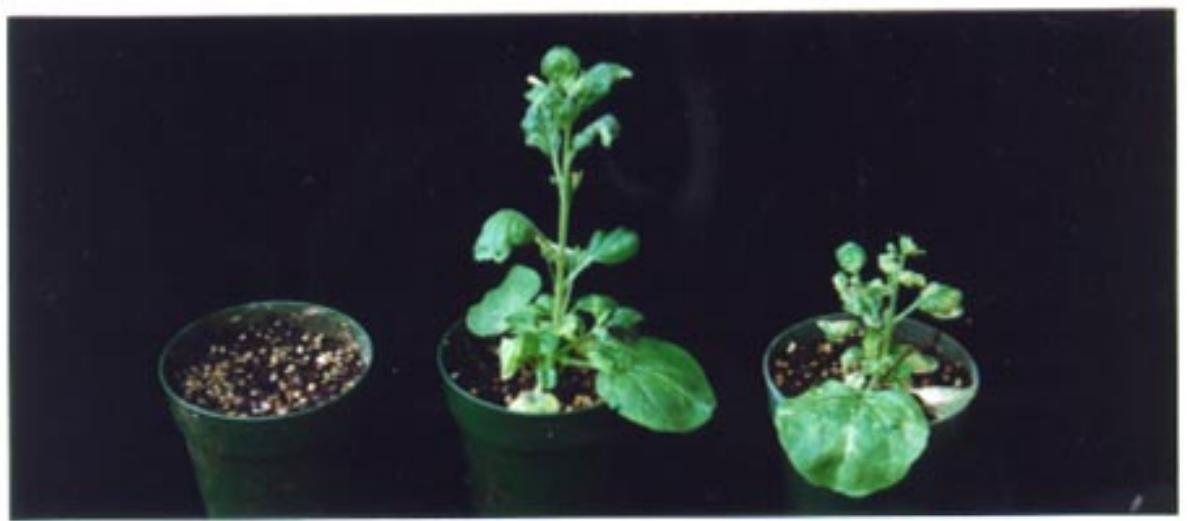

B
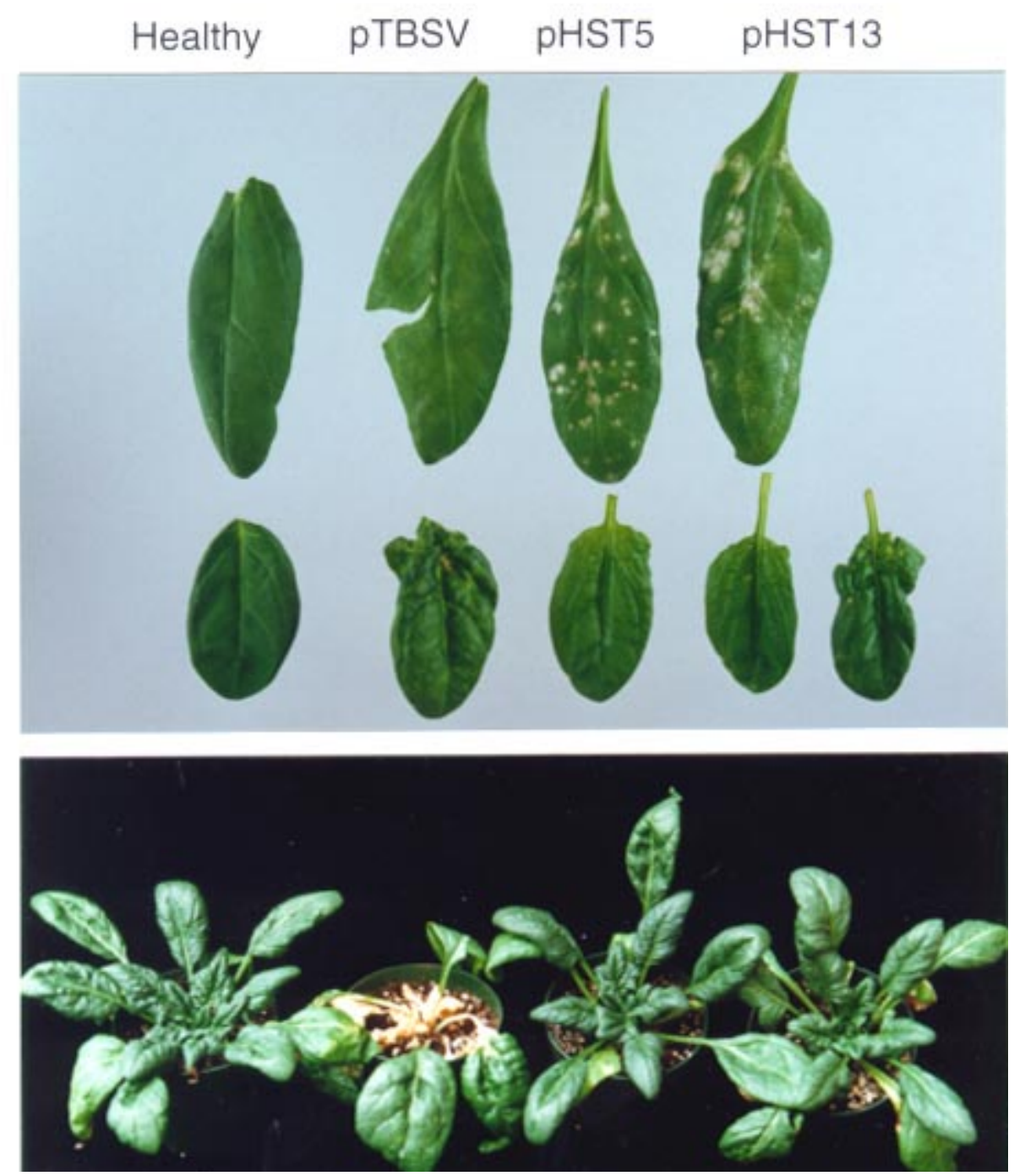

Fig. 6. Symptoms caused by translational start site context mutants on Nicotiana benthamiana and spinach plants. A, Systemic symptoms on N. benthamiana 4 weeks after inoculation with transcripts from plasmids indicated above each plant. B, Symptoms on spinach. Top panel: First true spinach leaves inoculated 6 days previously with transcripts from plasmids indicated on top. Middle panel: Upper leaves from those plants are shown underneath at 7 days post inoculation (leaves from two different pHST13-inoculated plants are shown). Bottom panel: Spinach plants 4 weeks after inoculation with transcripts. 
A

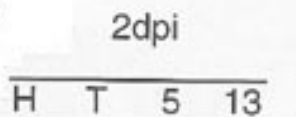

$4 \mathrm{dpi}$
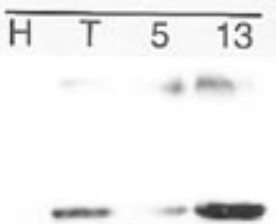

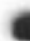
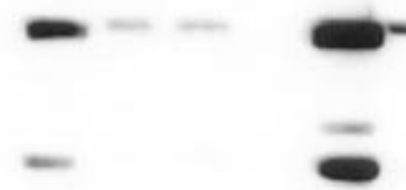
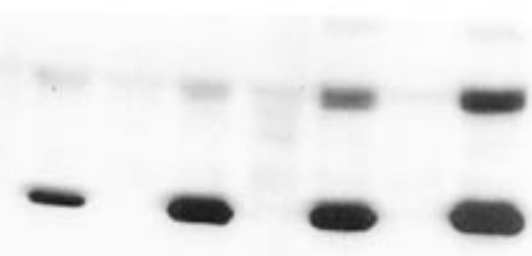

p22
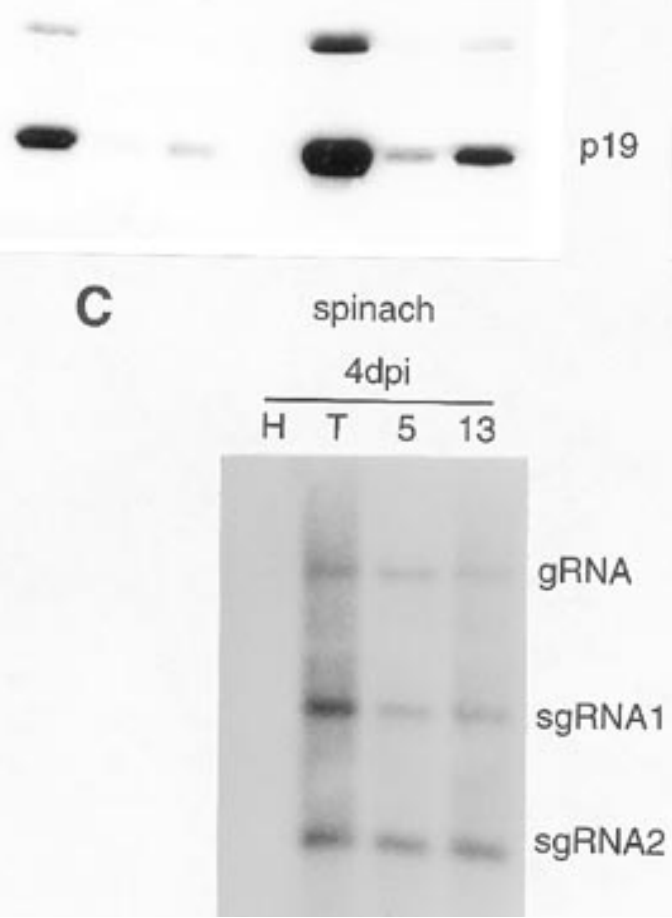

Fig. 7. Accumulation of tomato bushy stunt virus (TBSV) proteins and RNAs in plants. Immuno-detection of viral proteins in (A) Nicotiana benthamiana and (B) spinach leaves harvested at 2 or 4 days post inoculation with transcripts from either pTBSV-100 (T), pHST5 (5), or pHST13 (13), H represents a sample from healthy plants. The blot with $N$. benthamiana samples was subjected to horse radish peroxidase-mediated chemiluminescence whereas the proteins in spinach were detected with a standard alkaline phosphatase catalyzed color precipitation reaction. For p19 and p22 proteins, an additional band is present that probably represents a dimer of those proteins. The asterisk adjacent to the Western blot (immunoblot) for p41 protein indicates the position of coat protein break-down products. C, Northern (RNA) analyses of total RNA from spinach leaves inoculated 4 days previously with transcripts. 
of the p22 start codon to the AUG of p19, creating a sub-optimal context for p19 (CCAGCAUGGA), prevents the detectable accumulation of p19 protein in protoplasts, although the RNA replicates as efficiently as wild type (Scholthof et al. 1995b).

Our results agree with those obtained upon in vitro translation of CNV sgRNA2 transcripts, in combination with a transient reporter gene expression study with a cDNA segment encompassing the relevant start codons (Johnston and Rochon 1996). Those experiments also suggest that context sequences contribute to the differential accumulation of the p22 and p19 protein analogues encoded by this tombusvirus.

The combined evidence suggests that the relatively "weak" translational start site context of TBSV p22 provokes a high incidence of leaky scanning of ribosomes (Kozak 1995) that subsequently efficiently initiate translation at the optimal context of the downstream AUG for p19. When the start codon context for p22 is improved, less leaky scanning occurs, explaining the accompanying decrease in translation from the downstream AUG of p19. Presumably, contextdependent leaky scanning is permitted to operate because certain relevant features of sgRNA2 comply with criteria listed by Kozak (1995), which include the following: a short, nontranslated leader (approximately $16 \mathrm{nt}$ ); in analogy with $\mathrm{CNV}$, absence of an obvious stable secondary structure between the AUG of p22 and the downstream AUG of p19 (Johnston and Rochon 1996); and, relatively close proximity (29 nt) of the two start codons.

It would be expected that a substantial reduction in p19 translation via inhibition of leaky scanning would equally improve translation of $\mathrm{p} 22$. Therefore, our observation that improvement of the p22 start codon context only slightly enhances its translation, despite its strong reducing effect on p19 translation, at first sight may seem counter-intuitive in context of the above interpretation. However, it is possible that initiation of translation from p22 is the rate limiting step, irrespective of the context. In this scenario, a sufficient pool of small ribosomal subunits continuously line up upstream of the p22 start codon. Consequently, the overall levels of p22 translation are only modestly affected, regardless of whether or not a substantial number of small ribosomal subunits are stimulated to scan forward to the downstream start codon of p19.

\section{Changes in p22 protein levels do not impair cell-to-cell movement.}

The replacement of the adjacent leucine and proline amino acids to two serines in the $\mathrm{N}$ terminus of the $\mathrm{p} 22$ protein produced by RNA from pHST5 yielded a mutant p22 protein with a cell-to-cell movement activity comparable to that observed for its wild-type analogue. Other phenotypic effects observed with this mutant are comparable to those obtained with pHST13, which produces a wild-type p22 protein. Therefore, it appears that the biological effects, discussed in more detail below, are mostly due to variations in $\mathrm{p} 22 / \mathrm{p} 19$ protein dosage rather than to the two p22 amino acid mutations.

The observation that the mutant p22 protein of pHST5 was undetectable in protoplasts and plants is probably due to its poor recognition by the "polyclonal" antiserum. This interpretation is based on recent experiments in which the p22 proteins of wild type and pHST5 have been expressed to similar amounts in E. coli; but, in contrast to the wild-type protein, the mutant $\mathrm{p} 22$ protein is very poorly recognized upon immunodetection assays. This unexpected finding is currently a topic of investigation.

The introduction of mutations in pHST13 or pHST5 that altered the $\mathrm{p} 22 / \mathrm{p} 19$ protein ratio had no noticeable debilitating effect on replication, transcription, or cell-to-cell movement, nor on the ability to systemically infect $N$. benthamiana. However, recent experiments suggest that p22/p19 context mutations may influence virus movement in cowpea, a local lesion host in which the p19 protein contributes to localized spread (data not shown). Therefore, it cannot be ruled out that effects on cell-to-cell movement may occur in other hosts that were not included in this study. Host-dependent effects have also been reported for a particular cucumber mosaic virus (CMV) strain whose substantially elevated levels of the cellto-cell movement protein permitted the establishment of more severe chronic infections in N. tabacum (Gal-On et al. 1996).

The effect of the mutations on the $\mathrm{p} 22 / \mathrm{p} 19$ protein ratio was associated with a reduction in coat protein accumulation (Fig. 7), but a mutant devoid of p19 expression (Scholthof et al. 1995b) failed to obviously show this effect (B. Desvoyes, unpublished results). These data, in combination with recent tests, suggest that the coat protein reduction effect can mostly be attributed to increased translation of p22. The molecular mechanism responsible for the putative regulation of coat protein reduction is currently being investigated.

\section{Changes in $\mathbf{p 2 2 / p 1 9}$ protein ratios affect symptom induction.}

The results illustrate that reduced p19 protein accumulation diminished the severity of necrosis in systemically infected $N$. benthamiana plants. This is consistent with earlier findings that the p19-mediated apical necrosis on this host is dramatically attenuated in the presence of defective interfering RNAs (DIs), which also cause a substantial reduction in $\mathrm{p} 19$ protein accumulation (Scholthof et al. 1995c).

Previous results showed that a TBSV mutant devoid of p19 expression gave rise to chlorotic areas (Scholthof et al. 1995a) on $N$. tabacum, but unspecified resistance mechanisms still prevented infection of upper leaves. The present study illustrates that a decrease in p19-elicitor accumulation results in enlarged areas of chlorotic/necrotic infection on inoculated $N$. tabacum leaves. These results suggest that the p19-mediated localized necrosis contributes to the efficiency of the HR-like defense, but an additional level of resistance is operational that is separate from the necrotic response. A separation of $\mathrm{HR}$ and resistance was recently also reported for CMV in cowpea (Kim and Palukaitis 1997).

The altered ratios of $\mathrm{p} 22 / \mathrm{p} 19$ protein accumulation appeared to stimulate the onset of slightly smaller necrotic local lesions on $N$. glutinosa. In analogy with the p19/N. tabacum system it is tempting to interpret this as a biological confirmation that the levels of p22 elicitor are initially enhanced, resulting in earlier and more effective onset of resistance responses. However, although a slight early increase of p22 protein was observed for pHST13, the protein produced by pHST5 was poorly recognized by the antiserum, which impacts the ability to enforce this statement. It is plausible that the $N$. glutinosa lesion phenotype is also influenced by a reduction in the necrosis-inducing p19 protein, and by possible host-dependent effects of the serine substitutions in the modified $\mathrm{p} 22$ protein encoded by pHST5. 


\section{Relationship between p19 protein dosage and virus spread.}

Recent molecular genetic studies have permitted the identification of several virus genes and host factors that are required for efficient virus spread (Carrington et al. 1996; Gilbertson and Lucas 1996; Nelson and van Bel 1998; Séron and Haenni 1996). Complementation experiments with furovirus replicons also suggest that coordinated expression of triple gene block genes is important for cell-to-cell movement of these viruses (Bleykasten-Grosshans et al. 1997). The present study shows a comparable level of control because efficient systemic spread of TBSV through spinach plants requires a ratio of $\mathrm{p} 22 / \mathrm{p} 19$ in favor of abundant $\mathrm{p} 19$ protein accumulation.

Whether the p19 protein is directly involved in movement or indirectly through possible interference with defense responses (including gene silencing) remains to be elucidated. A p19-mediated interference with defense systems would agree with the observation that the mutants that produce less p19 protein give rise to necrotic local lesions on inoculated spinach leaves whereas under the same conditions such lesions were shown to be absent on leaves inoculated with wild-type TBSV (Fig. 6B). Within this context it is possible that due to over-expression of $\mathrm{p} 22$ protein additional defense responses are erected by the mutants pHST5 and pHST13, which in combination with a reduced accumulation of $\mathrm{p} 19$ protein may prohibit invasion of spinach.

Combined, the p19-associated features allude to the possibility that this protein is required to create a suitable environment for a virus infection. In the context of Samuel's observation that TMV movement occurs from the inoculated leaves toward the roots (Samuel 1934), the "front-line" activity of p19 protein would be consistent with our preliminary findings that the p19 protein rapidly accumulates in spinach roots before any other virus protein can be detected (H. Scholthof, unpublished results).

The observation that the function of a virus protein relies on its abundant expression is an aspect that thus far has received limited attention. In many molecular genetic studies reported to date, mutations are often introduced to measure a phenotypic response without careful examination of protein accumulation. The present study, it is hoped, emphasizes the importance of monitoring the effect of genetic mutations on protein levels and detectability before accurate conclusions can be drawn about functionality. This is especially important in those instances when an amino acid substitution affects protein stability or folding, as one could easily arrive at the erroneous conclusion that a particular amino acid or region is directly involved in molecular interactions required for the function of that protein.

\section{MATERIALS AND METHODS}

\section{Protocols.}

Standard molecular biology protocols were carried out (Sambrook et al. 1989), or as recommended by the suppliers of reagents. Previous reports (Scholthof et al. 1993b, 1995a, 1995b, 1994) describe RNA analysis, hybridization protocols, protein analyses, immuno-detection, bio-assays, and reporter gene expression studies with plants and protoplasts. Random primed pHS49 (Scholthof and Jackson 1997) was used as the hybridization probe in Northern (RNA) analyses. Spinach plants (cv. Trias), N. tabacum, N. glutinosa, N. clevelandii, and $N$. benthamiana were grown in climate-controlled growth chambers $\left(14 \mathrm{~h}\right.$ of daytime at 24 to $26^{\circ} \mathrm{C}$, nighttime at $22^{\circ} \mathrm{C}$ ), or maintained in the greenhouse.

Transcripts for in vitro translation were generated from PCR products amplified from pTBSV-100, pHST5, and pHST13 (Fig. 1). Transcripts of comparable templates from pHS157 and pHS136 that are inactive for $\mathrm{p} 19$ or p22 production, respectively (Scholthof et al. 1995b), served as controls. The PCR products were generated with forward primers "T7RNA2wt" or "T7RNA2mut," which contain a T7 polymerase promoter immediately upstream of the sequences corresponding to the $5^{\prime}$ end of sgRNA2 (Hillman et al. 1989). The 3' terminal end of these forward primers contained either wild-type sequences surrounding the ATG of p22 ("T7RNA2wt") or the mutant sequences ("T7RNA2mut") (Fig. 1). For all PCRs, the reverse primer " 3 '-27mer" was used, which anneals at the $3^{\prime}$ end of the TBSV genome. Transcripts resembling sgRNA2 were generated in vitro and transcript yield was estimated based on ethidium bromide staining after agarose gel electrophoresis. Similar amounts of transcripts were translated in wheat germ or rabbit reticulocyte lysates, in the presence of $\left[{ }^{35} \mathrm{~S}\right]$ methionine as described elsewhere (Scholthof and Jackson 1997).

\section{Recombinant plasmids.}

The nucleotide sequences are presented at the DNA level because these were subjected to manipulations. However, throughout the Results and Discussion, nucleotides are presented as viral RNA sequences. Plasmid pHST5 was constructed by the following strategy: a PCR was performed with pHS173 (Scholthof et al. 1995d) as a template with "TBSVcp" (containing the unique BamHI site) as a forward primer, and the reverse primer "p19/p22 switch" (Fig. 1A). The "p19/p22 switch" primer contains the mutations indicated for pHST5 in Figure 1C, and a unique HpaI site at its $5^{\prime}$ end. The blunt-ended PCR fragment was ligated into SmaIdigested pKAN2 (Scholthof et al. 1995a) to yield pHST4-15. This plasmid was digested with BamHI and HpaI, and the released fragment was used to replace the $N c o$ I (filled-in with DNA Polymerase I Klenow fragment) to the BamHI fragment of pHS45 (Scholthof et al. 1993b), which contains the GUS gene. The use of pHS45 as the acceptor plasmid permitted convenient screening for replacement of the GUS gene segment with the fragment from pHST4-15. Correct fusion of the blunt-end HpaI terminus from pHST4-15 with the filled-in NcoI site from pHS45 would yield the desired mutated sequence upstream of the underlined ATG of p19 in the sequence $5^{\prime}$...AGTTCATGG....3', thereby removing the original NcoI site (Fig. 1). In addition, the introduction of a mutation at the original PflMI site upstream of the ATG for p22 to yield the sequence $5^{\prime}$..AAACCATGG..3' introduced a new $\mathrm{NcoI}$ site (Fig. 1). Restriction enzyme and sequence analyses confirmed that all the mutations and fusions were correctly introduced into pHST5.

For construction of plasmid pHST13, the forward PCR primer "T7RNA2mut" (Fig. 1) was used in combination with a reverse primer covering the SmaI site at the $3^{\prime}$ end of pTBSV-100 ("3'-27mer"; Fig. 1A). The amplified fragment was digested with PflMI and SalI, to replace the corresponding fragment of pHST5. The introduction of the new fragment 
restored the original wild-type sequences surrounding the ATG of p19, including the original NcoI site. Consequently, pHST13 contained two NcoI sites, one at the ATG of p22 and one at the ATG of $\mathrm{p} 19$, as was confirmed by restriction analyses and sequencing. To histochemically evaluate the effect of mutations with GUS assays, pHST23 and pHST24 were generated. For this purpose, PCR fragments were amplified with "TBSVcp" and "p19/p22 switch" primers (Fig. 1) with pHS45 (Scholthof et al. 1993b) as template, and these products were cleaved with PflMI and NotI to replace the corresponding fragments of pHST5 and pHST13, respectively. Sequence analyses were used to confirm the mutations.

\section{ACKNOWLEDGMENTS}

We are grateful to Steve Garcia for technical assistance, and Mike Hughes and Gino Medrano for assistance in PVX-mediated expression experiments. At various stages of the experimentation we received very helpful advice and assistance from Massimo Turina and Karen-Beth G. Scholthof, whom we also would like to thank, together with Jong-Won Park, Ana Maria R. da Silva, Wenping Qiu, and Rob Noad, for helpful suggestions during the preparation of the manuscript. We thank Rogers Sandoz Seeds for generous supplies of spinach seeds. This work was funded by grants from USDA/CSREES-NRI-CGP (95-37303-2289) and the Texas Higher Education Coordinating Board Advanced Research Program (999902-056).

\section{LITERATURE CITED}

Bleykasten-Grosshans, C., Guilley, H., Bouzoubaa, S., Richards, K. E., and Jonard, G. 1997. Independent expression of the first two triple gene block proteins of beet necrotic yellow vein virus complements virus defective in the corresponding gene but expression of the third protein inhibits viral cell-to-cell movement. Mol. Plant-Microbe Interact. 10:240-246.

Carrington, J. C., Kasschau, K. D., Mahajan, S. K., and Schaad, M. C. 1996. Cell-to-cell and long distance transport of viruses in plants. Plant Cell 8:1669-1681.

Chu, M., Park, J.-W., and Scholthof, H. B. 1999. Separate regions on the tomato bushy stunt virus p22 protein mediate cell-to-cell movement versus elicitation of effective resistance responses. Mol. PlantMicrobe Interact. 12:285-292.

Dinesh-Kumar, S. P., and Miller, W. A. 1993. Control of start codon choice on a plant viral RNA encoding overlapping genes. Plant Cell 5: 679-692.

Gal-On, A., Kaplan, I. B., and Palukaitis, P. 1996. Characterization of cucumber mosaic virus: II. Identification of movement protein sequences that influence its accumulation and systemic infection in tobacco. Virology 226:354-361.

Gilbertson, R. L., and Lucas, W. J. 1996. How do viruses traffic on the 'vascular highway'? Trends Plant Sci. 1:260-268.

Hayes, R. J., Brunt, A. A., and Buck, K. W. 1988. Gene mapping and expression of tomato bushy stunt virus. J. Gen. Virol. 69:3047-3057.

Hearne, P. Q., Knorr, D. A., Hillman, B. I., and Morris, T. J. 1990. The complete genome structure and synthesis of infectious RNA from clones of tomato bushy stunt virus. Virology 177:141-151.

Hillman, B. I., Hearne, P., Rochon, D. A., and Morris, T. J. 1989. Organization of tomato bushy stunt virus genome: Characterization of the coat protein gene and the $3^{\prime}$ terminus. Virology 169:42-50.

Johnston, J. C., and Rochon, D. M. 1990. Translation of cucumber necrosis virus RNA in vitro. J. Gen. Virol. 71:2233-2241.

Johnston, J. C., and Rochon, D. M. 1996. Both codon context and leader length contribute to efficient expression of two overlapping open reading frames of a cucumber necrosis virus bifunctional subgenomic mRNA. Virology 221:232-239.

Kim, C.-H., and Palukaitis, P. 1997. The plant defense response to cucumber mosaic virus in cowpea is elicited by the viral polymerase gene and affects virus accumulation in single cells. EMBO J. 16: 4060-4068.

Kozak, M. 1981. Possible role of flanking nucleotides in recognition of the AUG initiator codon by eukaryotic ribosomes. Nucleic Acids Res. 9:5233-5252.

Kozak, M. 1995. Adherence to the first-AUG rule when a second AUG codon follows closely upon the first. Proc. Natl. Acad. Sci. USA 92: 2662-2666.

Kozak, M. 1997. Recognition of AUG and alternative initiator codons is augmented by $\mathrm{G}$ in position +4 but is not generally affected by the nucleotides in positions +5 and +6. EMBO J. 16:2482-2492.

Lutcke, H. A., Chow, K. C., Mickel, F. S., Moss, K. A., Kern, H. F., and Scheele, G. A. 1987. Selection of AUG initiation codons differs in plants and animals. EMBO J. 6:43-48.

Nelson, R. S., and van Bel, A. J. E. 1998. The mystery of virus trafficking into, through and out of vascular tissue. Cell Biol. Physiol. 59: 476-533.

Rochon, D. M., and Johnston, J. C. 1991. Infectious transcripts from cloned cucumber necrosis virus cDNA: Evidence for a bifunctional subgenomic mRNA. Virology 181:656-665.

Sambrook, J., Fritsch, E. F., and Maniatis, T. A. 1989. Molecular Cloning: A Laboratory Manual. 2nd ed. Cold Spring Harbor Laboratory, Cold Spring Harbor, NY.

Samuel, G. 1934. The movement of tobacco mosaic virus within the plant. Ann. Appl. Biol. 21:90-111.

Scholthof, H. B., Borja, M., Morris, T. J., and Jackson, A. O. 1993a. Molecular approaches for control of tomato bushy stunt virus. Pages 239-249 in: Molecular biology of tomato: Fundamental Advances and Crop Improvement. J. I. Yoder, ed. Technomic Pub., Lancaster, PA.

Scholthof, H. B., and Jackson, A. O. 1997. The enigma of pX: A host dependent cis-acting element with variable effects on tombusvirus RNA accumulation. Virology 237:56-65.

Scholthof, H. B., Morris, T. J., and Jackson, A. O. 1993b. The capsid protein gene of tomato bushy stunt virus is dispensable for systemic movement and can be replaced for localized expression of foreign genes. Mol. Plant-Microbe Interact. 6:309-322.

Scholthof, H. B., Scholthof, K.-B. G., and Jackson, A. O. 1995a. Identification of tomato bushy stunt virus host-specific symptom determinants by expression of individual genes from a potato virus $\mathrm{X}$ vector. Plant Cell 7:1157-1172.

Scholthof, H. B., Scholthof, K.-B. G., Kikkert, M., and Jackson, A. O. 1995b. Tomato bushy stunt virus spread is regulated by two nested genes that function in cell-to-cell movement and host-dependent systemic invasion. Virology 213:425-438.

Scholthof, K.-B. G., Hillman, B. I., Modrell, B., Heaton, L. A., and Jackson, A. O. 1994. Characterization and detection of sc4: A sixth gene encoded by Sonchus yellow net virus. Virology 204:279-288.

Scholthof, K.-B. G., Scholthof, H. B., and Jackson, A. O. 1995c. The effect of defective interfering RNAs on the accumulation of tomato bushy stunt virus proteins and implications for disease attenuation. Virology 211:324-328.

Scholthof, K.-B. G., Scholthof, H. B., and Jackson, A. O. 1995d. The tomato bushy stunt virus replicase proteins are coordinately expressed and membrane associated. Virology 208:365-369.

Séron, K., and Haenni, A.-L. 1996. Vascular movement of plant viruses. Mol. Plant-Microbe Interact. 9:435-442.

Sivakumaran, K., and Hacker, D. L. 1998. The 105-kDa polyprotein of southern bean mosaic virus is translated by scanning ribosomes. Virology 246:34-44.

Zhou, H., and Jackson, A. O. 1996. Expression of the barley stripe mosaic virus RNA $\beta$ “triple gene block”. Virology 216:367-379. 